\title{
Nutritional supplements and the EU: is anyone happy?
}

\author{
Christine Eberhardie \\ Faculty of Health and Social Care Sciences, Kingston University and St George's, University of London, 2nd Floor, \\ Grosvenor Wing, Cranmer Terrace, London SW17 ORE, UK
}

\begin{abstract}
In 2000 an estimated $£ 335 \times 10^{6}$ was spent on food supplements and herbal remedies in the UK. Until recently, The Trades Description Act 1968, the Food Safety Act 1990 and The Food Labelling Regulations 1996 (amended 2004) were the only form of regulation available to protect the public. The medical community has been concerned about the risk to patients of inaccurate dosages and poor-quality products as well as drug-nutrient and nutrient-nutrient interactions. Following growing concern about the type and quality of food supplements and herbal remedies available in the EU, the European Commission has published directives regulating food supplements (2002/46/EC) and herbal remedies (2004/24/EC and 2004/27/EC) available within the EU. The directives came into force in 2005 and limit the number and quality of permitted food supplements through the creation of a 'positive list' of approved supplements. In the present paper the new regulatory frameworks and the implications for the food supplement manufacturers, traditional and complementary therapists, the healthcare professions and patients will be examined. It would appear that there is considerable dissatisfaction with the regulations in their present form. Several questions remain: is regulation the answer; who decides which nutrients go on the positive list; what effect has the regulation had on patient safety and patient choice?
\end{abstract}

\section{EU regulations: Food supplements: Herbal remedies}

There has been an increase in the use of nutritional supplements of all kinds in the last 20 years. In addition, the EU has expanded from six member states in 1957 to twenty-seven in 2007. With such an expansion there are many wider considerations that need to be taken into account, apart from the specific EU directive and subsequent regulations on food supplements. Some EU member states use a considerable amount of vitamin and mineral supplements and have introduced regulation (e.g. Germany), while others use them to a much lesser extent. Each country varies in the extent and process of regulatory control.

In commercial terms the estimated expenditure in 2000 on food supplements and herbal remedies in the UK alone was $£ 335 \times 10^{6}$ according to a Mintel survey ${ }^{(1)}$, which constitutes an important part of EU revenue.

In the present paper the background, rationale and content of the EU directives and regulations on food supplements and related directives will be discussed and an attempt will be made to determine whether consumers in general and the frail and sick in particular are satisfied with them.

\section{The regulation of food supplements and herbal remedies before the directives}

In the UK the legislation covering the regulation of the sale of food supplements was The Trades Description Act $1968^{(2)}$, the Food Safety Act $1990^{(3)}$ and The Food Labelling Regulations $1996^{(4)}$. It was generally agreed that there were major shortcomings in this legislation.

There was no clear and accepted definition until the drafting of the EU Directive on Food Supplements (2002/ $46 / \mathrm{EC})^{(5)}$, and according to the full regulatory impact report no specific legislation on food supplements ${ }^{(6)}$.

\section{The background to the directives}

There are many reasons for the development of the EU Directive on Food Supplements $(2002 / 46 / E C)^{(5)}$. First, the $\mathrm{EU}$ is a free market and anything that infringes the free movement of goods and services within the EU will attract the attention of the European Commission on the grounds that it could indicate a contravention of the Treaty of Rome. Much of the harmonisation of European activity is 
done through the drafting and agreement of EU directives. Second, there is a need for common public safety standards within the EU and for products entering the EU from elsewhere.

Nutritionists and healthcare professionals responsible for advice and maintenance of adequate nutrition in both healthy and sick individuals are concerned about the increase in the availability and use of high-dose vitamins and minerals in retail outlets in the high street and on the internet $^{(7)}$. The public, however, has a different perception. Patients when asked why they take vitamin and mineral supplements, some in very high doses, will give one or more of the following reasons:

(a) a lack of confidence in the vitamin and mineral content of food that has been: stored for a long time, e.g. fruit that has been picked before it is ripe, and has travelled long distances before it reaches the shop; grown in soil that has been overused;

(b) a desire to ensure that their nutrient intake is well balanced, especially if they have an aversion to some foods or a lifestyle that gives them less control over their diet;

(c) a belief that certain vitamins and minerals in high doses will prevent disease and improve immunity and healing in acute and chronic ill health;

(d) beliefs that vitamins and minerals bought over the counter are safe when taken alone or with other prescribed medicine;

(e) a desire to prevent ill health and avoid hospital treatment;

(f) a desire to prevent deterioration in health while on a hospital waiting list.

The scientific basis for these fears and decisions is shaky but public perception is very powerful and has led to a marked increase in UK sales of food supplements. Data from the Food Standards Agency ${ }^{(8)}$ indicate that over the 5 -year period 2001-6 there was a rise (from $£ 335 \times 10^{6}$ to $\left.£ 550 \times 10^{6}\right)$ in the revenue from sales.

For food supplements there was no clear unambiguous definition before the EU Directive was drafted. In addition, the widening of EU membership gave rise to some concern about the illegal import of herbal substances and food supplements, which would be difficult to police. The WHO has expressed concern over the increase in counterfeit drugs $^{(9)}$ that are reported to have a global street value of $>$ US $\$ 35 \times 10^{9(10)}$, and while this aspect is not the main concern of those producing food supplements, it is important to ensure that there are no loopholes in legislation that allow drugs to be packaged as dietary supplements or herbal remedies and vice versa. There is evidence that herbal remedies are being mixed with synthetic drugs with serious consequences for the consumer ${ }^{(11)}$. Health, police and customs authorities worldwide require clearer guidance on which nutrients and herbal remedies are legal and safe ${ }^{(12)}$.

Each directive is specific and those working closely with the directives either in the production or use of food supplements and herbal remedies need to ensure that where there is overlap it is discussed and an outcome agreed. The directives have led to national regulations in each member state.

The definition of 'food supplements' used in Article 2 of EU Directive 2002/46/EC is: ' $\ldots$ foodstuffs the purpose of which is to supplement the normal diet and which are concentrated sources of nutrients or other substances with a nutritional or physiological effect, alone or in combination, marketed in dose form, namely forms such as capsules, pastilles, tablets, pills and other similar forms, sachets of powder, ampoules of liquids, drop dispensing bottles, and other similar forms of liquids and powders designed to be taken in measured small unit quantities, ${ }^{(5)}$. The term 'nutrients' in the Directive and subsequent regulations refers to vitamins and minerals.

\section{The content of the EU Directive on Food Supplements}

EU Directive 2002/46/EC ${ }^{(5)}$ recognises that there are legitimate reasons for supplementing a normal diet but that there must be specific rules on the nutrients that are included. Thus, the concept of the 'positive list' was introduced, which includes thirteen vitamins with thirty-two allowable sources and fifteen minerals with eighty allowable sources.

Manufacturers or suppliers whose products have not been evaluated and are not on the positive list have until the end of 2009 to apply for derogation to the competent authorities in the member states. In the UK this stipulation has resulted in a flurry of applications and, in answer to a parliamentary question in the House of Commons in July 2006, the Minister of State for Health stated that dossiers had been received for 421 substances seeking derogation ${ }^{(13)}$. It is difficult to imagine the nature of such a huge number of applications and to what extent the applications are valid.

The responsibility for the safety of food supplements under this Directive lies with the European Food Safety Authority, which is also tasked with determining the safe maximum and minimum levels of vitamins and minerals. To that end the European Commission have produced a discussion paper on the topic ${ }^{(14)}$. At present they are concentrating on maximum levels and the difficulty is finding the right model to use to ascertain which levels to choose and why. The responses to the discussion paper have highlighted the need for an agreed model for determining the appropriate maximum levels that protect the public but at the same time preserve informed choice for the consumer ${ }^{(15)}$.

Some stakeholders favour the model provided by the UK Expert Group on Vitamins and Minerals ${ }^{(15,16)}$ on safe upper limits of vitamins and minerals, while others favour the German model ${ }^{(17)}$. There are other models from Europe and negotiations are taking place to establish which one will be chosen.

\section{The other related $\mathrm{EU}$ directives}

Discussion of the EU Directive for Food Supplements cannot be seen totally in isolation from the other EU 
directives related to the safety of food and herbal medicines. In particular, there are the directives related to traditional herbal medicines (Directive 2004/24/EC) ${ }^{(18)}$, food labelling (Directive 2003/89/EC) ${ }^{(19)}$ and the conduct of clinical trials for medicinal products for human use (Directive 2001/20/EC) ${ }^{(20)}$.

Herbal medicines are very popular but there have been growing concerns that there are insufficient controls on the sale of them. It has been reported in a study of the sale of common herbal remedies such as Echinacea (Echinacea angustifolia), ginseng (Panax spp.), garlic (Allium sativum L.) and kava kava (Piper methysticum) that there were $>400$ internet sites, of which 149 claim that their products would treat, prevent or even cure particular diseases ${ }^{(21)}$.

The aim of the EU directive relating to traditional herbal remedies is to improve patient public safety and ensure that herbal medicinal products that are available within the EU are made with agreed ingredients and are clearly labelled without exaggerated claims being made for the product. This process involved amendments to the EU Directive on Medicinal Products for Human Use (2001/83/ EC amended by $2004 / 27 / E C)^{(22)}$. In addition, the only traditional herbal remedies permitted are those with a known efficacy following 30 years of use, 15 years of which have to have been within the EU.

Is anyone happy? A transcript of emails sent to the BBC News in $2005^{(23)}$, in response to their question, reflects a wide range of opinions. The following is a sample of the opinions expressed:

there is no need for more regulation and it is seen as an interference from Brussels. The exponents of this argument are convinced that the European Commission is eroding the individual's freedom of choice. They ask the question: do we need more regulation?;

the EU Directive is more about a free market than patient safety and reflects the power of the large pharmaceutical companies over the small manufacturers'; the Directive should not be restricted to vitamins and minerals but should cover all alternative medicine.

In addition, healthcare professionals and nutritionists have expressed concern about the poor control over the purity of products sold and the claims made about them ${ }^{(10,24,25)}$. Professionals and public alike are concerned that the EU must join forces with the rest of the international community to find ways of regulating the sales of counterfeit and dangerous medicines, nutrients and supplements on the internet $^{(9,21,26)}$. Since the directives were signed there have been discussions about this issue ${ }^{(21)}$.

Some doctors and other healthcare professionals welcome the legislation but consider that the directives do not go far enough, that the individual directives can bring further confusion and that issuing licences is not an end to the problem ${ }^{(27,28)}$. They believe that regulation is essential but that the directives related to food law are numerous and complex and do not reduce confusion because of the terms used. For example, there is lack of clarity as to whether a substance is a nutrient, a herb, a food supplement or a medicinal product. This confusion is illustrated in relation to garlic because it can be sold as plant, food and herb. It is also produced chemically and sold in tablet form as a herbal medicinal product ${ }^{(29)}$. A detailed review of the current actual and forthcoming legislation has demonstrated the complexity of the legislation and points out that even now there is no regulatory framework for 'neutraceuticals' or 'functional foods' ${ }^{(30)}$. If doctors, pharmacologists and nutrition scientists are concerned about the lack of clarity and the potential for confusion, what chance does the public have?

The manufacturers as represented by the Health Food Manufacturers Association ${ }^{(31)}$, and user organisations such as the Alliance for Natural Health ${ }^{(32)}$ and the Herbal Society ${ }^{(33)}$ are committed to a safe scientific basis for consumer protection but are concerned that the positive lists for both food supplements and herbal remedies do not recognise existing products that they consider to have been used safely for a number of years.

\section{Conclusion}

It can be seen that the whole area of regulation for food supplements and traditional herbal remedies is complex and necessary but controversial. From the consumer perspective and that of a potential patient it is crucial that this commerce is conducted honestly and transparently and with the safety of the public overriding commercial interests.

\section{References}

1. Mintel International Ltd (2001) Complementary Medicines: Market Intelligence. London: Mintel International Ltd.

2. UK Parliament (1968) The Trades Description Act 1968. London: H.M. Stationery Office.

3. UK Parliament (1990) Food Safety Act 1990 (c. 16). http:// www.opsi.gov.uk/acts/acts1990/Ukpga_19900016_en_1.htm

4. UK Parliament (1996) Statutory Instrument 1996 no. 1449, The Food Labelling Regulations 1996. http://www.opsi.gov. uk/SI/si1996/Uksi_19961499_en_1.htm

5. European Commission (2002) Directive 2002/46/EC of the European Parliament and of the Council of 10 June 2002 on the approximation of the laws of the Member States relating to food supplements. Official J EC L183, 51-57.

6. Food Standards Agency Expert Group on Vitamins and Minerals (2003) Safe Upper Limits for Vitamins and Minerals. London: Food Standards Agency.

7. Lewis JD \& Strom BL (2002) Balancing safety of dietary supplements with the free market. Ann Intern Med 136, 616661.

8. Food Standards Agency (2006) Survey to assess the market for high dose vitamin and mineral supplements in the UK and top determine the use of voluntary advisory statements. http://www.food.gov.uk/multimedia/pdfs/int060703.pdf (accessed June 2007).

9. World Health Organization (2006) Counterfeit medicines. Fact sheet no. 275, revised 14 November 2006. http:// www.who.int/mediacentre/factsheets/fs275/en/print.html (accessed 11 June 2007).

10. Cockburn R, Newton PN, Agyarko EK, Akunilli D \& White NJ (2005) The global threat of counterfeit drugs: Why industry and governments must communicate the dangers. PloS Medicine 2, e100; available at http://dx.doi.org/doi: 10.1371/journal.pmed.0020100 
11. Ernst E (2002) Adulteration of Chinese herbal medicines with synthetic drugs: a systematic review. J Intern Med 252, 107-113.

12. World Health Organization (2005) General information on counterfeit medicines. http://www.who.int/medicines/ services/counterfeit/overview/en/print.html

13. UK Parliament (2006) House of Commons Hansard Written Answers for 03 July 2006 (pt 1405). http://www.publications. parliament.uk/pa/cm200506/cmhansard/cm060704/text/60704 (accessed March 2007).

14. European Communities (2006) Discussion Paper on the Setting of Maximum and Minimum Amounts for Vitamins and Minerals in Foodstuffs. Brussels: EC Health and Consumer Protection Directorate-General; available at http://ec.europa. eu/food/food/labellingnutrition/supplements/discus_paper_ amount_vitamins.pdf (accessed June 2007).

15. UK Government (2006) Response to the Discussion Paper on the setting of maximum and minimum amounts for vitamins and minerals in foodstuffs. http://ec.europa.eu/food/food/ labellingnutrition/supplements/documents/uk_en.pdf

16. Government of Estonia (2006) Response to the Discussion Paper on the setting of maximum and minimum amounts for vitamins and minerals in foodstuffs. http://ec.europa.eu/food/ food/labellingnutrition/supplements/documents/estonia_en.pdf

17. Federal Republic of Germany (2006) Response to the Discussion Paper on the setting of maximum and minimum amounts for vitamins and minerals in foodstuffs. http://ec. europa.eu/food/food/labellingnutrition/supplements/documents/ bmelv_en.pdf

18. European Commission (2004) Directive 2004/24/EC of the European Parliament and of the Council of 31 March 2004 amending, as regards traditional herbal medicinal products, Directive 2001/83/EC on the Community code relating to medicinal products for human use. Official $J E U \mathbf{L 1 3 6}$, 85-90.

19. European Commission (2003) Directive 2003/89/EC of the European Parliament and of the Council of 10 November 2003 amending Directive 2000/13/EC as regards indication of the ingredients present in foodstuffs. http://europa.eu.int/ eur-lex/pri/en/oj/dat/2003/1_308/1_30820031125en00150018. pdf (accessed July 2007).

20. European Commission (2001) Directive 2001/20/EC of the European Parliament and of the Council of 4 April 2001 on the approximation of the laws, regulations and administrative provisions of the Member States relating to the implementation of good clinical practice in the conduct of clinical trials on medicinal products for human use. Official J EC L121, 34-44.

21. Morris CA \& Avorn J (2003) Internet marketing of herbal products. JAMA 290, 1505-1509.

22. European Commission (2004) Directive 2004/27/EC of the European Parliament and of the Council of 31 March 2004 amending Directive 2001/83/EC on the Community code relating to medicinal products for human use. Official $J E U$ L136, 34-57.

23. British Broadcasting Corporation (2005) 'Do you agree with European vitamin ruling?' http://news.bbc.co.uk/1/hi/talking_ point/4674841.stm

24. Barnes J (2003) Quality, efficacy and safety of complementary medicines: fashions, facts and the future. Part 1. Regulation and quality. Br J Clin Pharmacol 55, 226-233.

25. World Health Organization (2003) Traditional medicine. Fact sheet no. 134. http://www.who.int/mediacentre/factsheets/ fs134/en/print.html

26. European Food Safety Authority Scientific Committee (2004) Discussion paper on botanicals and botanical preparations widely used as food supplements and related products: coherent and comprehensive risk assessment and consumer information approaches. http://www.efsa.europa.eu/etc/ medialib/efsa/science/sc_commitee/sc_documents/616.Par. 0001.File.dat/scdoc_advice03_botanicals_en 1.pdf

27. De Smet PAGM (1995) Should herbal medicine-like products be licensed as medicines. Br Med J 310, 1023-1024.

28. Ferner RE \& Beard K (2005) Regulating herbal medicines in the UK. Br Med J 331, 62-63.

29. Kroes BH (2006) European perspective on garlic and its regulation. J Nutr 136, 732S-735S.

30. Coppens P, da Silva MF \& Pettman S (2006) European regulations on nutraceuticals, dietary supplements and functional foods: A framework based on safety. Toxicology 221, 59-74.

31. Health Food Manufacturers Association (2007) Position paper: Towards ensuring vitamin and mineral safety. http://www. hfma.co.uk/PositionPaperVitaminMineralSafety.pdf (accessed July 2007).

32. Alliance for Natural Health (2007) Alliance for Natural Health. http://www.alliance-natural-health.org/index.cfm (accessed July 2007).

33. The Herb Society (2005) A guide to the EU Traditional Herbal Medicines Directive and its possible implications. http:// www.herbsociety.co.uk/legislation.htm (accessed August 2005). 